\title{
Características físicas e físico-químicas de pitaia vermelha durante a maturação
}

\section{Physical and physico-chemical traits of red pitaya during ripeness}

\author{
Thatiane Padilha de Menezes ${ }^{1 *}$; José Darlan Ramos'; \\ Luiz Carlos de Oliveira Lima ${ }^{3}$; Ana Claudia Costa ${ }^{4}$; \\ Rita de Cássia Mirela Resende Nassur ${ }^{5}$; José Carlos Moraes Rufini ${ }^{6}$
}

Resumo

Devido ao aumento do consumo de frutos exóticos mundialmente, o cultivo da pitaia tem sido favorecido. Para incrementar o potencial agronômico da cultura, são necessários conhecimentos que visem o aumento da qualidade do fruto. Dessa forma, objetivou-se nesta pesquisa estudar características físicas e físico-químicas de pitaia vermelha durante a sua maturação, visando definir o estádio ótimo de colheita do fruto. Foram avaliados os seguintes parâmetros de qualidade: massa fresca do fruto, diâmetro longitudinal e transversal, cor de casca, firmeza da polpa, teores de sólidos solúveis, acidez titulável, ratio e pH. O delineamento experimental utilizado foi inteiramente casualizado, representado pelos períodos de coleta (dias após a antese). Em cada período de avaliação foram coletados sete frutos, representando as repetições, sendo um fruto em cada repetição. As médias dos períodos de avaliação foram submetidas à avaliação polinomial, sendo os modelos selecionados conforme a significância do teste $\mathrm{F}$ e do coeficiente de determinação. O ponto ideal para a colheita de pitaia vermelha ocorre aos 41 dias após a antese. Neste estádio, os frutos apresentaram maior massa e intensidade de coloração vermelha na casca, menor firmeza da polpa, maior teor de sólidos solúveis e menor acidez.

Palavras-chave: Pós-colheita, qualidade de fruto, dias após a antese, Hylocereus undatus Haw

\begin{abstract}
Due to the increase of exotic fruit consumption worldwide, the cultivation of dragon fruit has been favored. To increase the agronomic potential of the culture, knowledge aiming the increase of fruit quality is necessary. The aim of this study was to evaluate the physical-chemical and pyhisical characteristics of dragon fruit during maturation, in order to define the best harvest point. Fresh weight, longitudinal and transverse diameter, skin color, flesh firmness, soluble solids content, titratable acidity, ratio and flesh $\mathrm{pH}$ were evaluated. A completely randomized design was carried out, represented by harvest time (days after anthesis). In each evaluation time, seven fruits were harvested, representing the replications, being one fruit per parcel. The averages of each evaluation time were subjected to polynomial evaluation, being selected according to the significance of $\mathrm{F}$ test and the coefficient of determination. The best dragon fruit harvest time was observed 41 days after anthesis. At this stage, fruits presented higher weight and higher red skin color intensity, lower flesh firmness, higher contents of total soluble solids and lower acidity.
\end{abstract}

Key words: Postharvest, fruit quality, days after anthesis, Hylocereus undatus Haw

1 Eng ${ }^{\mathrm{a}} \mathrm{Agr}^{\mathrm{a}}$, Dr ${ }^{\mathrm{a}}$ em Agronomia, Universidade Federal de Lavras, UFLA, Lavras, MG. E-mail: thatiagro@yahoo.com.br

2 Eng $^{\mathrm{o}}$ Agr $^{\circ}$, Prof. Dr., Dept ${ }^{\circ}$ de Agricultura, UFLA, Lavras, MG. E-mail: darlan@dag@ufla.br

3 Farmácia e Bioquímica, Prof. Dr., Dept ${ }^{\circ}$ de Ciência dos Alimentos, UFLA, Lavras, MG. E-mail: lcolima@dca.ufla.br

4 Eng ${ }^{\mathrm{a}}$ Agr ${ }^{\mathrm{a}}, \mathrm{Dr}^{\mathrm{a}}$ em Agronomia, UFLA, Lavras, MG. E-mail: aninhamel@gmail.com

5 Eng $^{\mathrm{a}} \mathrm{Agr}^{\mathrm{a}}$, Dr ${ }^{\mathrm{a}}$ em Ciência dos Alimentos, UFLA, Lavras, MG. E-mail: ritarnassur@hotmail.com

6 Eng $^{\circ}$ Agr $^{\circ}$, Prof. Dr., Dept ${ }^{\circ}$ de Agronomia da Universidade Federal de São João Del Rei, Sete Lagoas, MG. E-mail: rufini@ufsj. edu.br

* Autor para correspondência 


\section{Introdução}

O gênero Hylocereus é um cacto americano de hábito variado e amplamente distribuído da Costa da Flórida ao Brasil, sendo seu fruto conhecido sob diversos nomes comerciais e nativos, prevalecendo mundialmente 'pitahaia' ou 'pitaya' (ORTIZHERNANDEZ; CARRILLO-SALAZAR, 2012) e no Brasil, pitaia.

No mundo existem três grupos de pitaia de valor comercial: a de casca vermelha e de polpa branca, Hylocereus undatus, a pitaia vermelha e de polpa vermelha, Hylocereus costarricenses, e a pitaia de casca amarela, com espinhos e polpa branca, Selenicereus megalanthus (COLOMBIA, 2011).

O fruto da pitaia é uma baga indeiscente, de formato globoso a elipsóide, com 10 a $12 \mathrm{~cm}$ de diâmetro (HERNÁNDEZ, 2000). Pode ser consumido in natura ou na forma de vinho, suco, geléia, iogurte, doce, conserva e outras sobremesas (HERBACH et al., 2006; SHETTY; RANA; PREETHAM, 2012).

Os frutos não são climatéricos (ZEE; YEN; NISHINA, 2004), assim devem estar no estádio ótimo de amadurecimento comestível à época da colheita e para que apresentem maior qualidade, devem ser deixados na planta até atingirem a composição desejável (CHITARRA; CHITARRA, 2005).

Em estudo de análise sensorial, Yah et al. (2008) relataram que a pitaia tem maior aceitabilidade quando colhida entre 25 e 31 dias após a antese e apresenta uma vida útil de 6 a 10 dias, quando armazenada em temperatura de 20 a $26^{\circ} \mathrm{C}$ (ARÉVALO-GALARZA; ORTIZ-HERNÁNDEZ, 2004; NERD; MIZRAHI, 1999).
A correta determinação do estádio de maturação do fruto é essencial para realizar a colheita no momento adequado (COELHO; CENCI; RESENDE, 2010). Dessa forma, são utilizados indicadores de maturação, que compreendem medidas físico-químicas, que sofrem alterações durante a maturação dos frutos (AZZOLINI; JACOMINO; SPOTO, 2004).

De acordo com Corrales (2003) pouco se conhece sobre os índices de colheita e o comportamento pós-colheita da pitaia, assim como os parâmetros de qualidade das diferentes espécies cultivadas. Diante disso, objetivou-se estudar neste trabalho as características físicas e físico-químicas de frutos de pitaia vermelha durante a sua maturação.

\section{Material e Métodos}

A pesquisa foi conduzida no setor de Fruticultura do Departamento de Agricultura da Universidade Federal de Lavras (UFLA) - MG. O município está situado a $21^{\circ} 14^{\prime} 06^{\prime}$ "de latitude S e $45^{\circ} 00$ '00" de longitude W, a uma altitude média de 918 metros (DANTAS; CARVALHO; FERREIRA, 2007). O clima da região é do tipo Cwa, segundo a classificação de Köppen. Os dados ambientais do período experimental estão demonstrados na Figura 1.

Para a condução do experimento foram utilizadas 20 plantas de pitaia vermelha [Hylocereus undatus (Haw.) Britton \& Rose], com cinco anos de idade, em espaçamento 3,0 × 3,0 m, tutoradas perpendicularmente ao solo, em mourões de eucalipto de 1,80 m. Na parte mediana de cada planta foram selecionados cladódios sadios, onde foram marcados 5 botões florais em estádio de desenvolvimento visualmente homogêneo, totalizando 100 botões florais. 
Figura 1. Valores de precipitação, temperatura e umidade relativa do ar durante os meses de janeiro (J), fevereiro (F) e março (M). Estação Climatológica do Departamento de Engenharia, Lavras-MG.

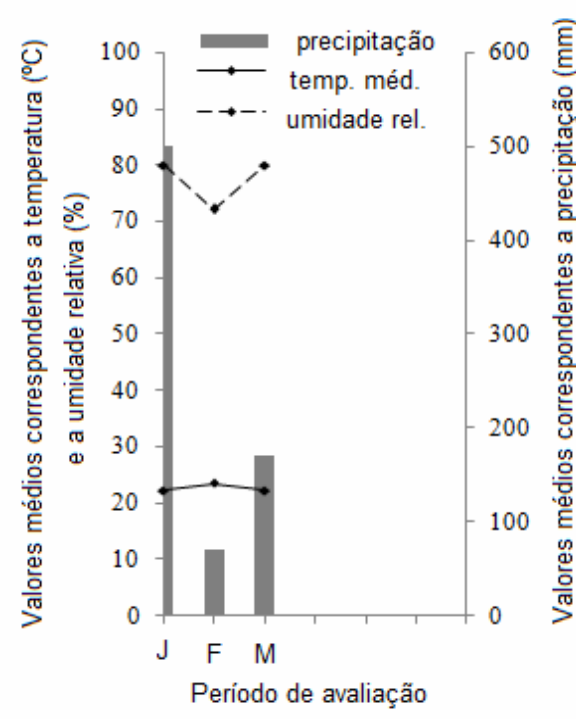

Fonte: Elaboração dos autores.

A partir da formação dos frutos, foram realizadas seis coletas (Figura 2), a cada 5 dias, para avaliações biométricas e físico-químicas dos frutos, realizadas no Laboratório de Pós-Colheita da Universidade Federal de Lavras, sendo analisadas as seguintes características:

a) Peso fresco do fruto obtido através de balança digital e expresso em gramas.

Diâmetro transversal e longitudinal avaliado através de um paquímetro digital e os resultados expressos em centímetro ( $\mathrm{mm})$.

b) Firmeza da polpa determinada com auxílio de um penetrômetro marca TR, modelo FT 327, com ponteira de $8 \mathrm{~mm}$, na região equatorial dos frutos, em pontos eqüidistantes, dos dois lados. Os resultados foram expressos em Newton (N.cm ${ }^{-2}$ ).

c) Os valores de coloração foram determinados com o auxilio do colorímetro Minolta, modelo CR-400, com iluminante $\mathrm{D}_{65}$ e no sistema CIE L*a*b*. As leituras dos valores foram feitas em quatro pontos aleatórios na casca do fruto de cada repetição. As coordenadas indicam: L* (brilho), a* (-a é verde/ + a é vermelho) e b (-b é $\mathrm{azul} / \mathrm{+b}$ é amarelo).

d) A concentração de sólidos solúveis (SS) foi realizada em refratômetro digital com compensação automática de temperatura, modelo PR-100 pallete (Atago Co, LTD, Japão), fazendo-se três leituras em cada amostra, a $20^{\circ}$ Celcius, sendo os resultados expressos em porcentagem (ASSOCIATION OF OFFICAL ANALITICAL CHEMISTS- AOAC, 2007). O preparo da amostra foi efetuado retirandose a polpa do fruto, triturada-a em politron, e o homogenato filtrado foi utilizado para a análise.

e) A acidez titulável (AT) foi determinada pesandose $1 \mathrm{~g}$ de polpa de fruto em balança analítica digital e posteriormente foi adicionado $20 \mathrm{~mL}$ de água destilada. Procedeu-se a trituração do material em politron, seguida de filtragem em organza. Foi acrescentada a solução três gostas do indicador fenolftaleína, procedendo-se as titulações com solução de $\mathrm{NaOH} 0,1 \mathrm{~N}$, sob agitação (INSTITUTO ADOLFO LUTZ, 1985). Os valores foram expressos em porcentagem de ácido málico. 
f) Relação SS/AT: obtido pelo quociente sólidos solúveis totais/acidez titulável.

g) $\mathrm{O} \mathrm{pH}$ foi determinado em duplicata, com as leituras feitas em um Phmetro digital, com valores variando de 0 - 14 (AOAC, 2007).

O delineamento experimental utilizado foi o inteiramente casualizado, representado pelos períodos de coleta. Em cada estádio de avaliação foram coletados sete frutos, representando as repetições, sendo um fruto em cada repetição. Os dados obtidos foram submetidos à análise de variância utilizando o programa Sisvar (FERREIRA, 2011). As médias dos períodos de avaliação foram submetidas à avaliação polinomial, sendo os modelos selecionados conforme a significância do teste $\mathrm{F}$ e do coeficiente de determinação.

Figura 2. Desenvolvimento de frutos de pitaia vermelha. $A=21$ dias após a antese, $B=26$ dias após a antese, $C=31$ dias após a antese, $\mathrm{D}=36$ dias após a antese, $\mathrm{E}=41$ dias após a antese, $\mathrm{F}=46$ dias após a antese.
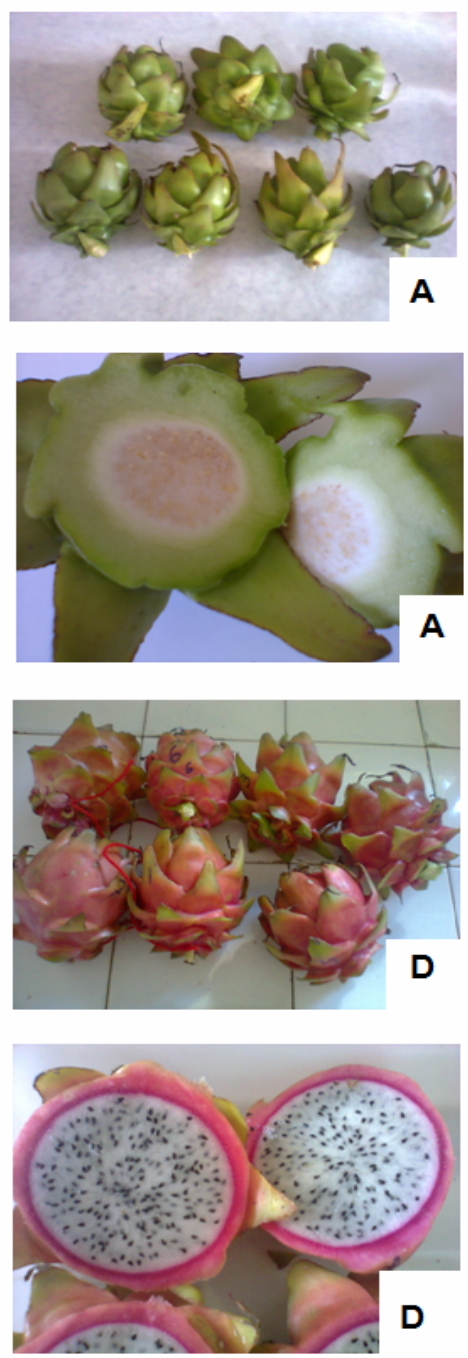

Fonte: Elaboração dos autores.
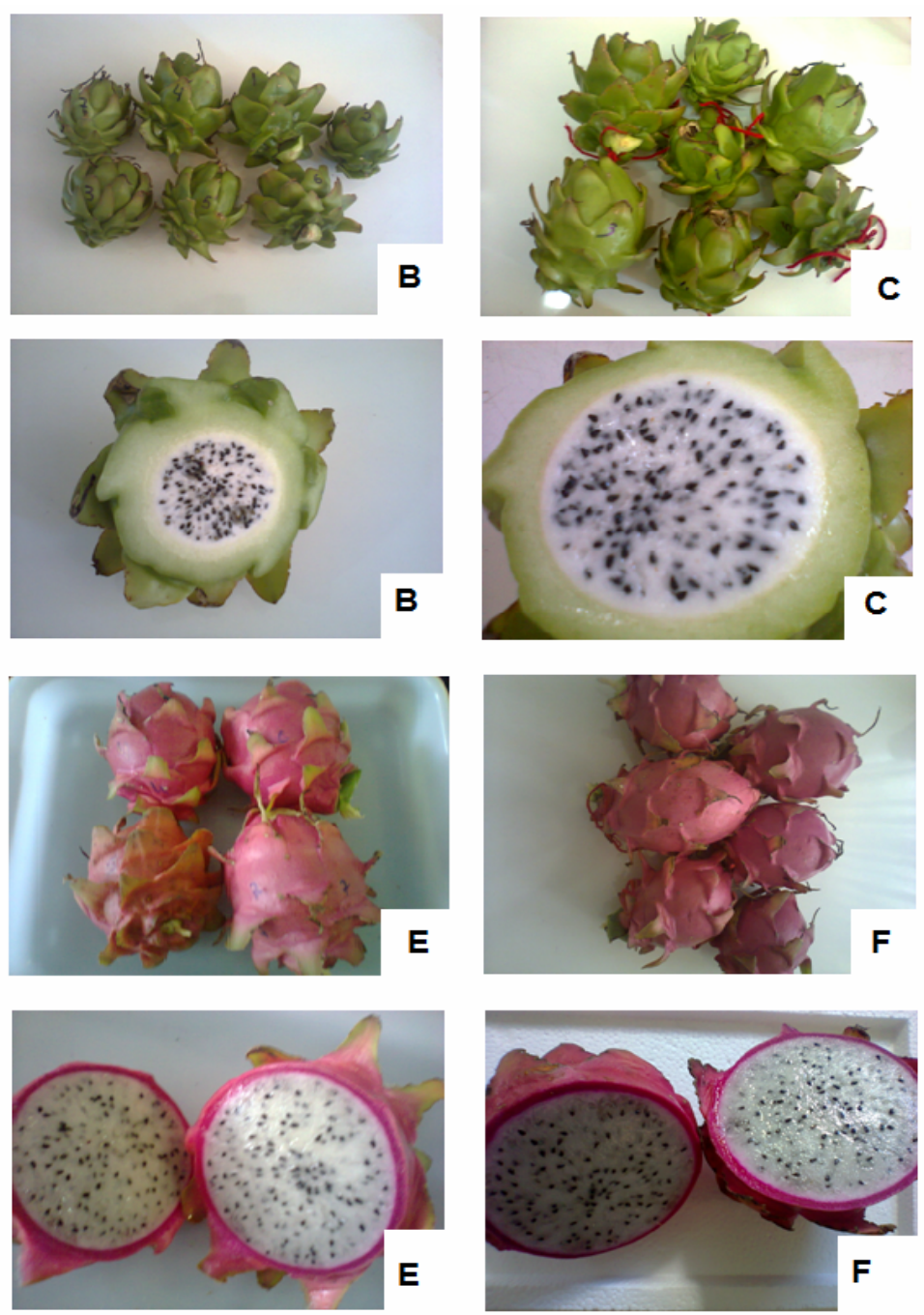


\section{Resultados e Discussão}

\section{Características fisicas}

Observou-se através da análise de variância que

o fator de variação período de coleta influenciou todas as características físicas avaliadas. As médias observadas ao longo da maturação da pitaia estão contidas na Tabela 1.

Tabela 1. Características físicas de pitaia vermelha durante a sua maturação.

\begin{tabular}{ccccccc}
\hline $\begin{array}{c}\text { Dias após a } \\
\text { antese }\end{array}$ & $\begin{array}{c}\text { Massa fresca do } \\
\text { fruto }(\mathrm{g})\end{array}$ & $\begin{array}{c}\text { Diâmetro } \\
\text { longitudinal }(\mathrm{mm})\end{array}$ & $\begin{array}{c}\text { Diâmetro } \\
\text { transversal }(\mathrm{mm})\end{array}$ & Valor L* & Valor a* & $\begin{array}{c}\text { Firmeza } \\
(\mathrm{N})\end{array}$ \\
\hline 21 & 135,11 & 67,26 & 62,09 & 47,91 & $-12,92$ & 20,94 \\
26 & 189,45 & 73,63 & 64,58 & 51,17 & $-12,61$ & 16,60 \\
31 & 257,67 & 82,50 & 69,17 & 54,81 & $-16,12$ & 17,09 \\
36 & 398,46 & 97,81 & 77,27 & 51,55 & 20,09 & 6,71 \\
41 & 442,47 & 98,73 & 83,41 & 51,23 & 35,50 & 6,16 \\
46 & 384,66 & 94,82 & 84,08 & 50,04 & 31,21 & 6,37 \\
\hline
\end{tabular}

Fonte: Elaboração dos autores.

A massa fresca dos frutos apresentou um comportamento cúbico no desenvolvimento da pitaia vermelha (Figura 3), atingindo um peso máximo de 442,47 g (Tabela 1), observando-se um decréscimo deste valor a partir de 41 dias após a antese. Para Wills et al. (1998), uma perda de peso superior a $5 \%$ pode ser suficiente para diminuir a qualidade em diferentes frutos. Possivelmente, a redução do peso na maturação final do fruto está relacionada à desidratação. Silva et al. (2006) relatam que a perda de massa é acentuada quanto maior o grau de amadurecimento do fruto, chegando a níveis elevados na senescência, quando não está mais apto a comercialização.

De acordo com Rodríguez et al.(2005) a perda de água por transpiração são maiores em frutas maduras, provavelmente devido ao evento da maturação, o qual requer uma elevada taxa de respiração, que por sua vez envolve geração de calor e perda de água.
Os valores da massa de fruto observados neste estudo são semelhantes aos encontrados na literatura. Yah et al. (2008) relatam peso de pitaia vermelha, aos 31 dias após a antese, de 469,2 g. Le Bellec, Vaillant e Imbert (2006) reportam que o peso dos frutos de Hylocereus undatus varia de 300 g a $800 \mathrm{~g}$.

O comportamento do diâmetro longitudinal da pitaia foi demonstrado por um modelo quadrático (Figura 4). Aos 41 dias após a antese, o fruto apresentou o diâmetro máximo de 98,76 mm, decrescendo em seguida. Já para o diâmetro transversal foi observado um incremento linear durante o desenvolvimento do fruto avaliado, sendo obtido o maior valor médio de $82,47 \mathrm{~mm}$ (Tabela 1). Já Yah et al. (2008) observaram um aumentou contínuo no tamanho da pitaia, que alcançou aos 31 dias após a antese $89 \mathrm{~mm}$ de diâmetro longitudinal e $82 \mathrm{~mm}$ de diâmetro transversal. 
Figura 3. Massa fresca de pitaia vermelha durante a maturação.

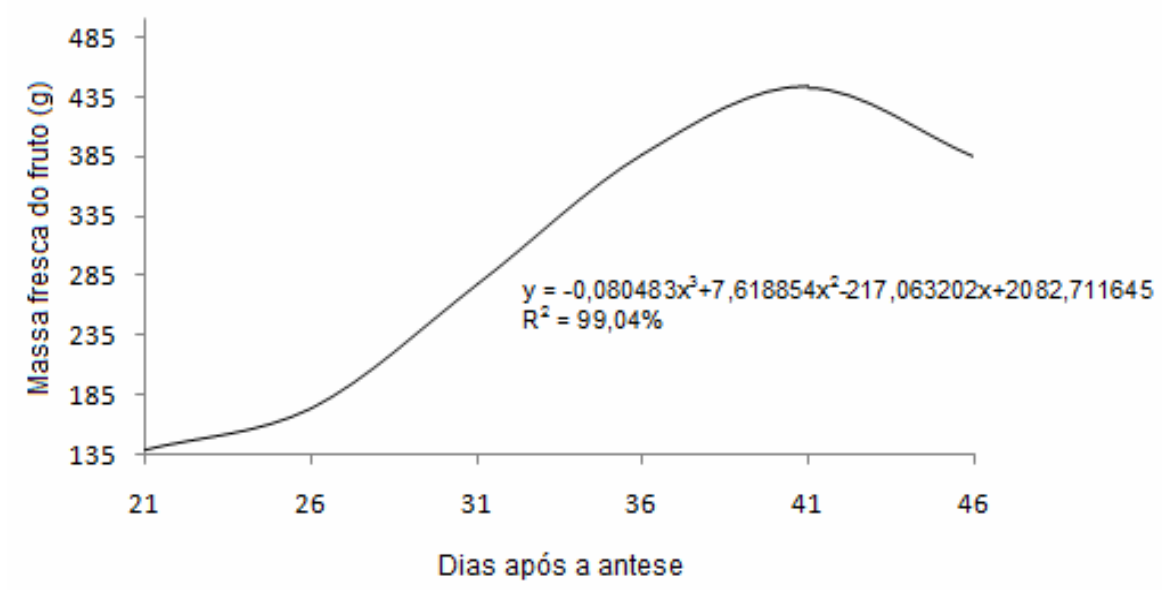

Fonte: Elaboração dos autores.

Figura 4. Diâmetro longitudinal de pitaia vermelha durante seu desenvolvimento.

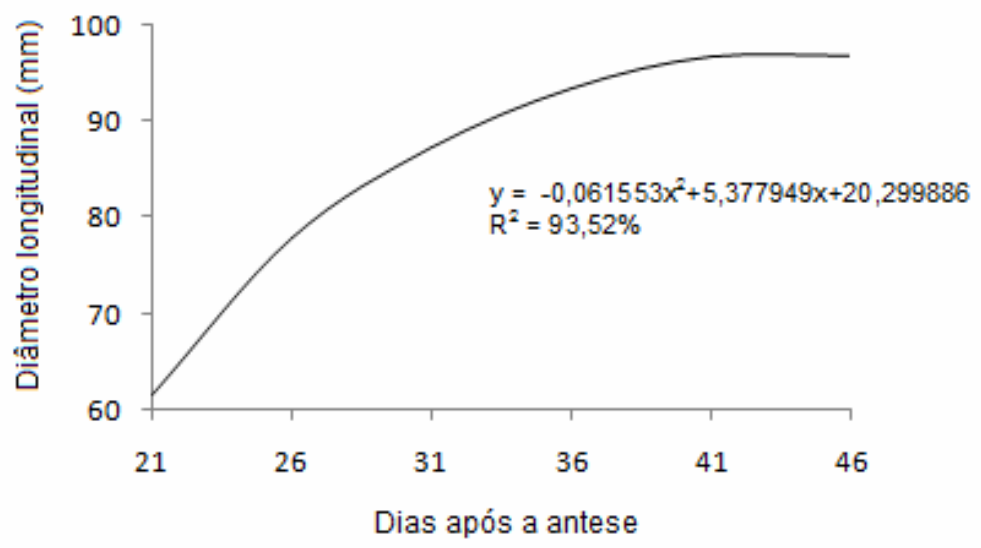

Fonte: Elaboração dos autores.

Figura 5. Diâmetro transversal de pitaia vermelha durante seu desenvolvimento.

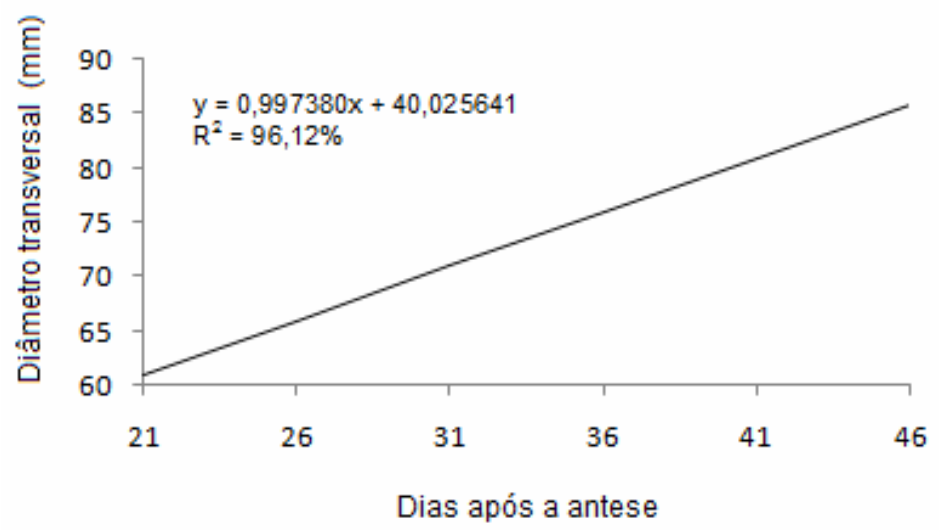

Fonte: Elaboração dos autores. 
Aos 21 dias após a antese, os frutos apresentaram uma coloração verde claro (Figura 2), ocorrendo uma rápida mudança da verde para o vermelho, dos 31 aos 36 dias após a antese. As brácteas mantiveram coloração verde durante o período estudado. Provavelmente neste período houve uma degradação da clorofila e a síntese de betacianinas. De acordo com Forni et al. (1992), as betacianinas são os pigmentos predominantes na casca dos frutos da maioria das cactáceas, responsáveis pela coloração vermelha durante o desenvolvimento do fruto. Aos 31 dias após a antese, Yah et al. (2008) observaram em estudos realizados no México, a coloração vermelha intensa em toda a casca de pitaia vermelha. Nerd e Mizrahi (1999) registram a primeira mudança de cor aos 24-25 dias após a antese e 4-5 dias mais tarde, os frutos adquirem coloração total, em condições de cultivo de a 25 a $30^{\circ} \mathrm{C}$, com irrigação e fertilização programada.

É possível observar, pelas Figuras 6 e 7 que os valores de $\mathrm{L}^{*}$ e de $\mathrm{a}^{*}$ aumentaram conforme o desenvolvimento do fruto, porém decrescem a partir dos 36 e 41 dias após a antese, respectivamente.

De acordo com To et al. (2002) o estádio ótimo de colheita para a pitaia vermelha pode ser indicada pela coordenada $\mathrm{a}^{*}$ e ocorre quando a casca encontra-se totalmente vermelha. Neste estudo, observou-se uma evolução do valor médio de $\mathrm{a}^{*}$, de $-12,92$ (21 dias após a antese) a 35,50 (41 dias após a antese) (Tabela 1).

Figura 6. Valores de $\mathrm{L}^{*}$ em pitaia vermelha durante seu desenvolvimento.

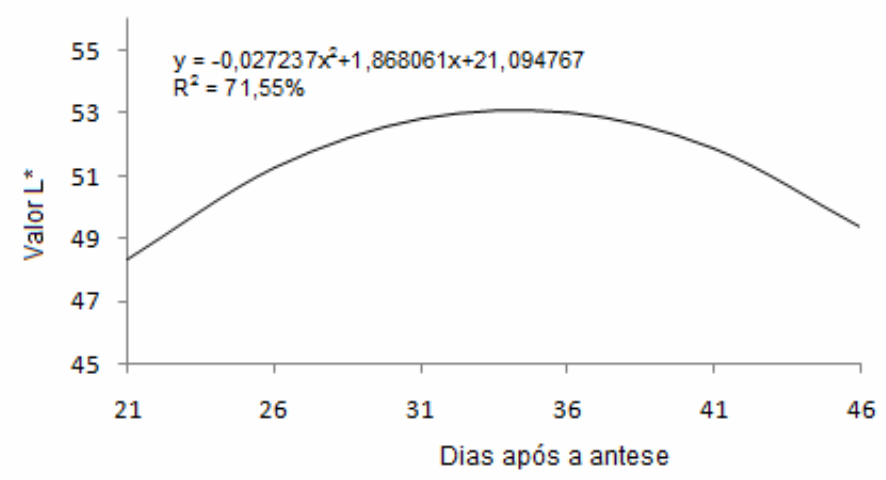

Fonte: Elaboração dos autores.

Figura 7. Valores de $\mathrm{a}^{*}$ em pitaia vermelha durante seu desenvolvimento.

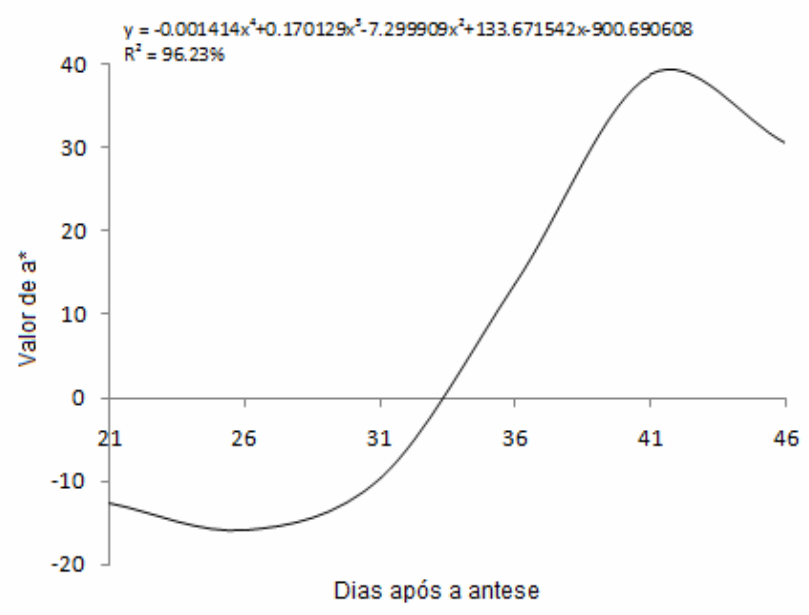

Fonte: Elaboração dos autores. 
A firmeza da polpa, conforme Fischer et al. (2011) é determinada pela força de coesão entre as pectinas. Neste estudo, observou-se um decréscimo do valor da firmeza com o decorrer do tempo (Figura 8), variando de 20,94 N a 6,16 N (Tabela 1), indicando um amaciamento da polpa. No entanto, a partir dos 41 dias após a antese o valor desta variável sofre um pequeno aumento. Possivelmente este acréscimo pode estar relacionado com a perda de água de pelo fruto. Valor semelhante $(6,3 \mathrm{~N})$ foi relatado por Yah et al. (2008), aos 31 dias após a antese.

As pectinas são os principais componentes químicos dos tecidos responsáveis pelas alterações de textura das frutas e hortaliças (Chitarra e Chitarra, 1990). Elevado número de enzimas tem participação na degradação biológica das substâncias pécticas, destacando-se as pectinametilesterase e a poligacturonases (SILVA et al., 2009).

De acordo com Enciso et al. (2011), a firmeza em frutos de Hylocereus undatus reduz consideravelmente quando alcançam a maturação completa. Este amolecimento da polpa da pitaia, para Yah et al. (1999) está relacionado com o aumento da atividade da enzima pectinametilesterase durante a maturação.

Figura 8. Firmeza da polpa de pitaia vermelha durante seu desenvolvimento.

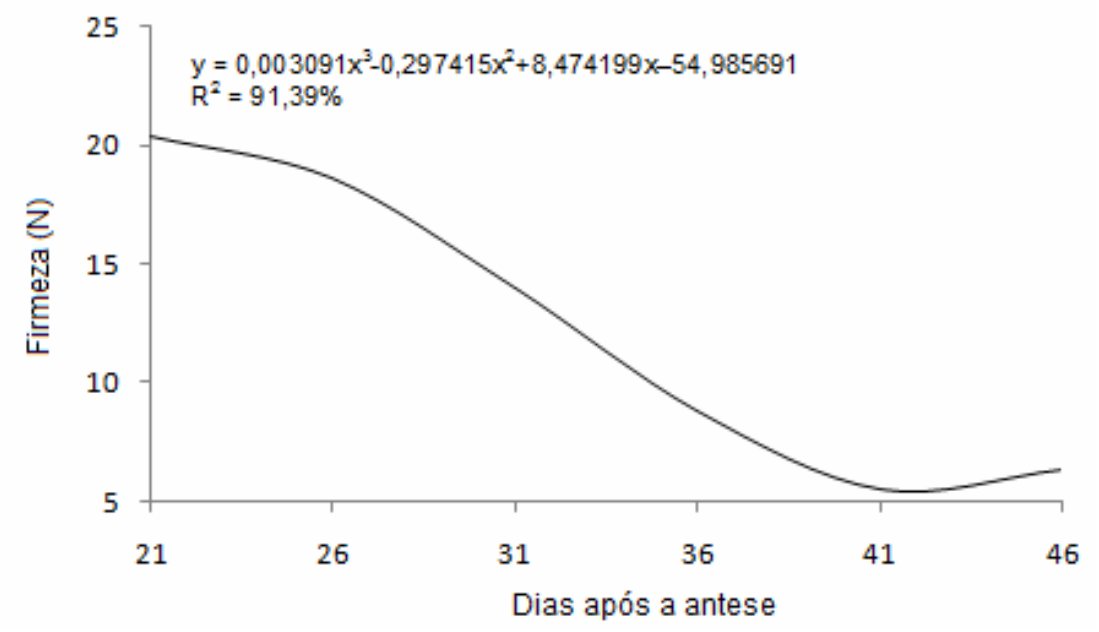

Fonte: Elaboração dos autores.

\section{Características físico-químicas}

A análise de variância revelou que o período de coleta alterou significativamente as características químicas dos frutos de pitaia. Os valores médios observados durante a maturação da pitaia encontramse na Tabela 2.

A acidez titulável da polpa da pitaia, medida em percentagem de ácido málico, durante a maturação, apresentou uma variação de $0,29 \%$ a 2,51\% (Tabela 2). Até os 31 DAA foi verificado um aumento da acidez e em seguida um decréscimo (Figura 9). Esta redução no valor da acidez ocorreu simultaneamente à mudança da coloração da casca do fruto. O acúmulo de ácidos orgânicos também foram verificados por Silva et al. (2005) em suco de maracujá, seguida de um declínio até o final do amadurecimento dos frutos. De acordo com Tucker (1993), os ácidos orgânicos durante o amadurecimento dos frutos, representam um dos principais substratos para os processos respiratórios, e de forma geral, tendem a diminuir durante esta fase. 
Redução da acidez titulável durante o após a floração, sendo observados valores 1,4 a amadurecimento da pitaia vermelha foram 0,4\% de ácido málico. Encisco et al. (2011) também verificados por Yah et al. (2008), dos 20 aos 31 dias constataram em pitaia uma redução de $80 \%$ na acidez do fruto durante o armazenamento.

Tabela 2. Características químicas de pitaia vermelha durante a maturação.

\begin{tabular}{ccccc}
\hline Dias após a antese & $\begin{array}{c}\text { Acidez Titulável } \\
(\mathrm{AT})(\%)\end{array}$ & $\mathrm{pH}$ & $\begin{array}{c}\text { Sólidos solúveis } \\
(\mathrm{SS})(\%)\end{array}$ & $\begin{array}{c}\text { Relação } \\
\text { SS/AT }\end{array}$ \\
\hline 21 & 0,29 & 5,35 & 3,43 & 12,49 \\
26 & 0,32 & 5,40 & 6,29 & 19,64 \\
31 & 2,51 & 3,62 & 9,58 & 3,80 \\
36 & 0,85 & 3,47 & 17,28 & 20,43 \\
41 & 0,51 & 3,77 & 19,58 & 39,14 \\
46 & 0,42 & 4,75 & 19,58 & 46,23 \\
\hline
\end{tabular}

Fonte: Elaboração dos autores.

Figura 9. Valores de acidez titulável da polpa de pitaia vermelha durante seu desenvolvimento.

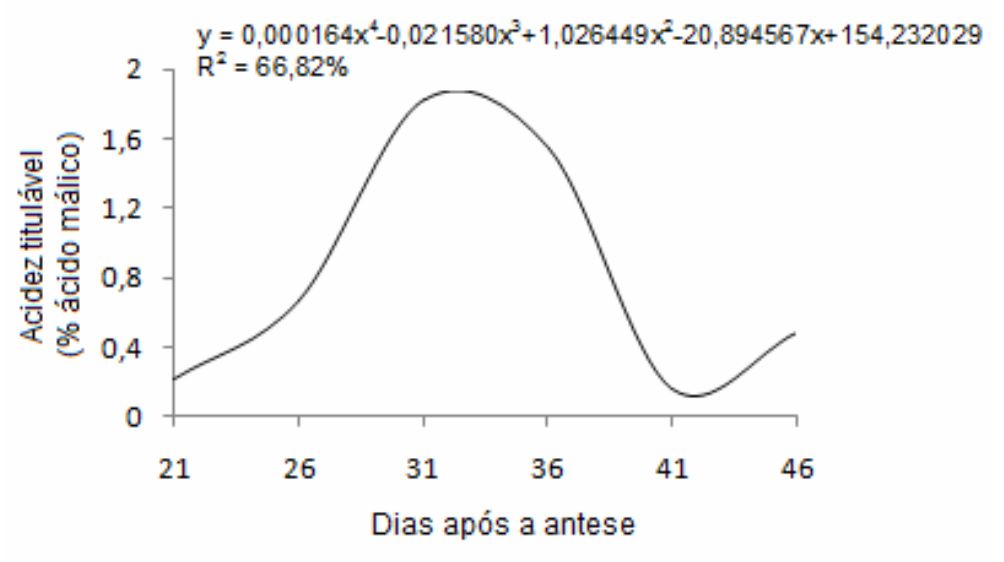

Fonte: Elaboração dos autores.

Já o pH apresentou comportamento inverso à acidez, reduzindo com a maturação dos frutos até aos 36 dias após a antese, aumentando em seguida (Figura 10). Este comportamento também foi observado por Silva et al. (2005), em suco de maracujá. Segundo os autores, a redução do $\mathrm{pH}$ pode estar atribuída ao acumulo de ácidos orgânicos, e o incremento do $\mathrm{pH}$ ao consumo os ácidos orgânicos durante o amadurecimento dos frutos, devido a atividade respiratória das células. Os valores de $\mathrm{pH}$ dos frutos nos três últimos estádios de maturação, quando adquiriram coloração vermelha da casca, variaram de 3,47 a 4,75 (Tabela 2).

Os teores de sólidos solúveis variaram de 3,4\% a $19,48 \%$ ao longo do desenvolvimento da pitaia (Tabela 2) sendo observados os maiores valores nos estádios finais de maturação (Figura 1). Este comportamento está de acordo com Chitarra e Chitarra (2005), os quais relataram que o teor de sólidos solúveis é dependente do estádio de maturação no qual o fruto é colhido, aumentando, geralmente, durante o amadurecimento devido à degradação de polissacarídeos. 
Figura 10. Valores de $\mathrm{pH}$ da polpa de pitaia vermelha durante seu desenvolvimento.

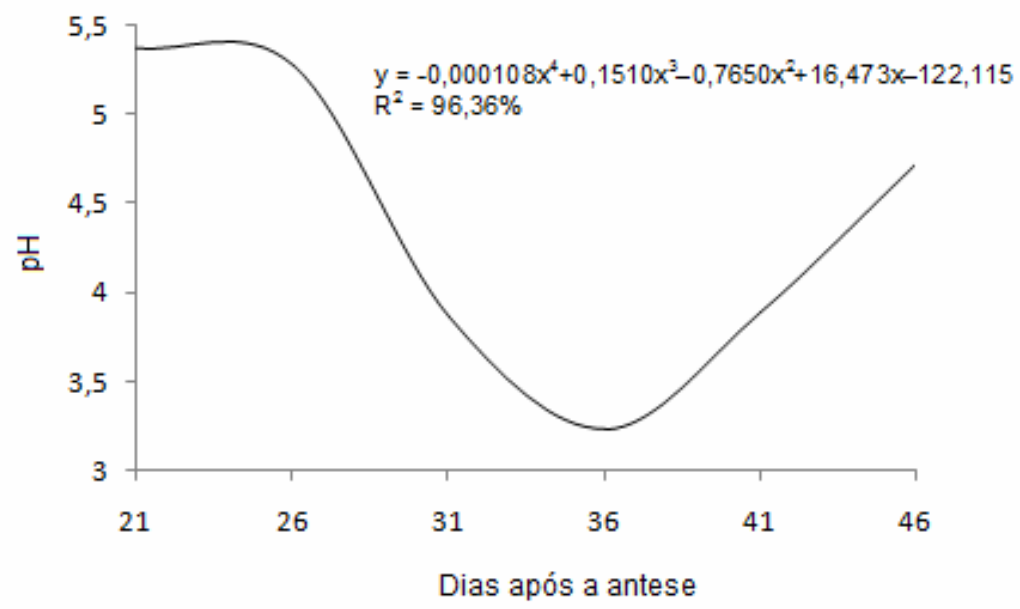

Fonte: Elaboração dos autores.

De acordo com Yah et al. (2008) há uma relação entre o desenvolvimento da cor e o incremento dos sólidos solúveis dos frutos. Estes autores registraram $4,6 \%$ aos 20 dias de desenvolvimento do fruto e aos 31 dias, 12,6\%. Merten (2003) relata teores de sólidos solúveis em frutos de pitaia vermelha, desenvolvidos na Califórnia, de $13 \%$ a $16 \%$. Provavelmente, a diferença encontrada entre os valores neste estudo e os dados da literatura citada estão relacionadas ao tipo de clima e à temperatura do local de cultivo.

Figura 11. Teores de sólidos solúveis em polpa de pitaia vermelha durante seu desenvolvimento.

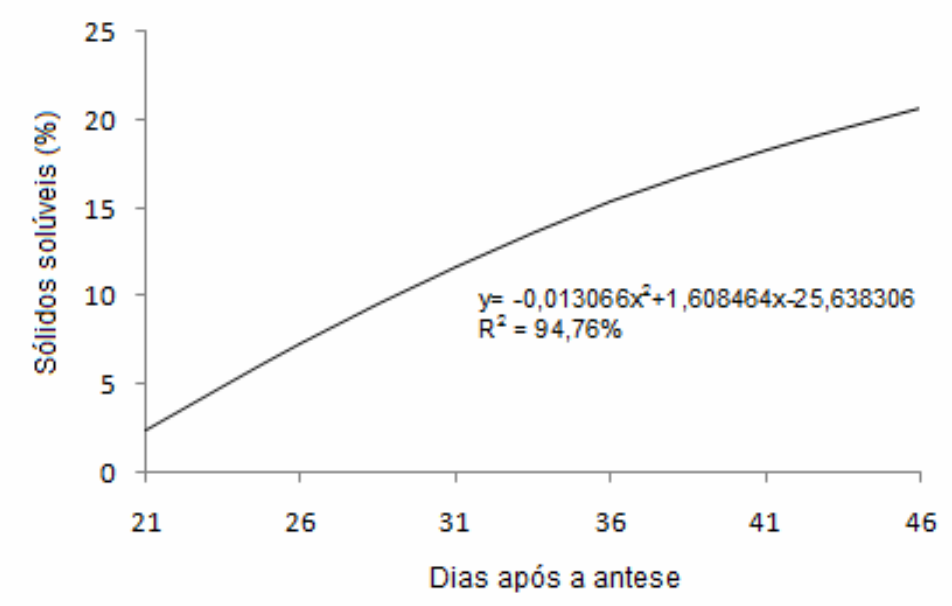

Fonte: Elaboração dos autores.

A relação SS/AT variou de 3,80 a 46,23 (Tabela longo da maturação da pitaia. De acordo com Nerd 2), aumentando durante a maturação do fruto, e e Mizrahi (1999) e To et al. (2002), para o consumo permanecendo praticamente constante nos estádios de frutos de Hylocereus undatus, o valor ideal da finais de desenvolvimento (Figura 11). Este aumento relação sólidos solúveis:acidez titulável é inferior a está relacionado com a baixa acidez registrada ao 40. De acordo com esses autores, neste estudo, valor 
inferior a 40 é observado aos 36 e 41 após a antese, quando os frutos apresentam coloração vermelha da casca. Yah et al. (2008) durante a maturação de pitaia vermelha relataram valores SS/AT de 3,4 (20 dias após o florescimento) a 33,5 (31 dias após o florescimento).

Dessa forma, é possível constatar através das características físicas e químicas da pitaia, que a colheita do fruto pode ser realizada aos 41 dias após a antese, onde foram verificados melhores valores para os parâmetros de qualidade. A partir deste período, há uma redução do tamanho final do fruto, aumento da firmeza e aumento da relação SS/AT, podendo ser um indício da senescência do fruto.
Diferentemente, Zee, Yen e Nishina (2004) relatam que a colheita da pitaia pode ser realizada 30 dias após a fixação do fruto. No entanto, o autor reporta que atrasar a colheita para 50 dias após o florescimento permite a obtenção de frutos mais doces e pesados. Ramírez (1999), ao avaliar acessos mexicanos de Hylocerus encontrou alta variação fenotípica da parte aérea, flores e frutos, observando que o amadurecimento da pitaia pode variar de 27 a 120 dias. Já Merten (2003), verifica que a maturação da pitaia, na California, ocorre entre 40 a 45 dias após a antese, período em que os frutos alcançam níveis máximos de sólidos solúveis, que variam de $13 \%$ a $16 \%$. Assim, percebe-se que período de colheita da pitaia é influenciado pelas condições edafoclimáticas e genéticas.

Figura 12. Relação SS/AT em pitaia vermelha durante seu desenvolvimento.

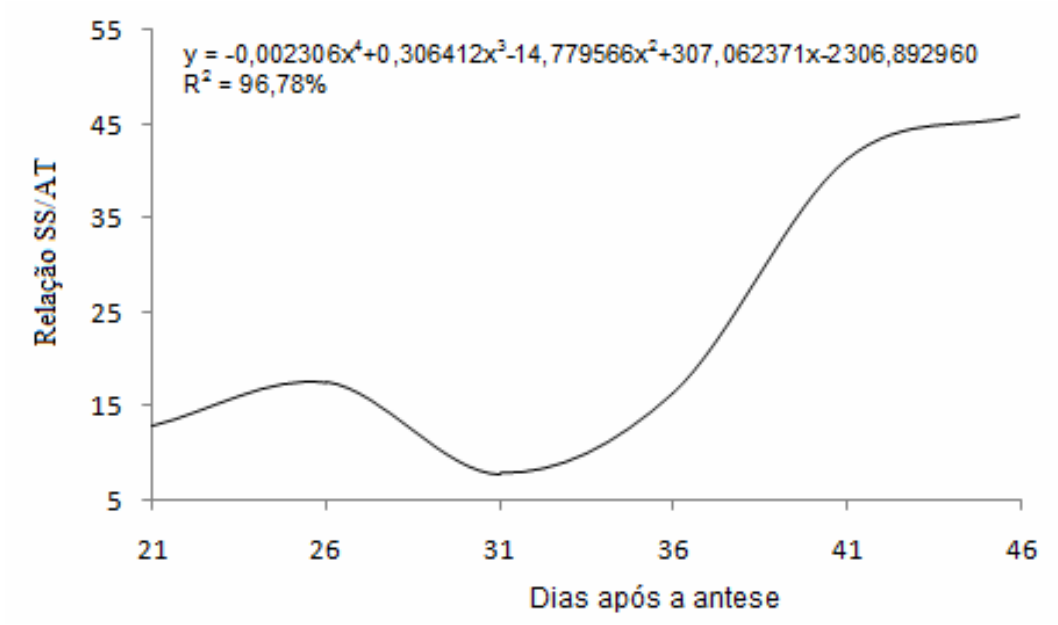

Fonte: Elaboração dos autores.

\section{Conclusões}

A maturação dos frutos de pitaia vermelha iniciase aos 36 dias após a antese, quando são observadas mudanças na tonalidade da casca, do verde para o vermelho. Nas condições ambientais onde foi desenvolvida a pesquisa, aos 41 dias após a antese, os frutos apresentaram maior massa, intensidade de coloração vermelha na casca e sólidos solúveis além de menor firmeza da polpa e acidez, sendo portanto, indicada a sua colheita.

\section{Referências}

ARÉVALO-GALARZA, M. L.; ORTIZ-HERNÁNDEZ, Y. D. Comportamiento poscosecha del fruto de la pitahaya (Hylocereus undatus). Cactaceas y Suculentas Mexicanas, San Pedro de los Pinos, año 49, n. 3, p. 8590, 2004.

ASSOCIATION OF OFFICAL ANALITICAL CHEMISTS - AOAC. Official methods of analysis of the Association of Official Analitical Chemists. $18^{\text {th }}$ ed. Washington: AOC, 2007. $1750 \mathrm{p}$. 
AZZOLINI, M.; JACOMINO, A. P.; SPOTO, M. H. F. Estádio de maturação e qualidade pós-colheita de goiabas 'Pedro Sato'. Revista Brasileira de Fruticultura, Jaboticabal, v. 26, n. 1, p. 29-31, abr. 2004.

CHITARRA, M. I. F.; CHITARRA, A. B. Pós-colheita de frutas e hortaliças: fisiologia e manuseio. Lavras: ESAL/FAEPE, 1990. 320 p.

Pós-colheita de frutas e hortaliças: fisiologia e manuseio. 2. ed. rev. e ampl. Lavras: UFLA, 2005. 785 p.

COELHO, A. A.; CENCI, S. A.; RESENDE, E. D. Qualidade do suco de maracujá-amarelo em diferentes pontos de colheita e após o amadurecimento. Ciência e Agrotecnologia, Lavras, v. 34, n. 3, p. 722-729, maio/jun. 2010.

COLOMBIA. Ministério de Agricultura y Desarrollo Rural. Agenda prospectiva de investigación y desarrollo tecnológico para cadena productiva de pitaya amarilla em Fresco em a Valle a Cauca. Bogotá, 2011. Disponível $\mathrm{em}: \quad<\mathrm{http} / / / \mathrm{www} \cdot \mathrm{minagricultura.gov.co/Paginas/inicio.}$ aspx>. Acesso em: 10 mar. 2013.

CORRALES, G. J. Caracterización, poscosecha, aprovechamiento e industrialización de pitayas y pitahayas. In: FLORES, C. A. (Ed.). Pitayas y pitahayas. Chapingo: Universidad Autónoma Chapingo, 2003. p. 137-173.

DANTAS, A. A. A.; CARVALHO, L. G.; FERREIRA, E. Classificação e tendências climáticas em Lavras, MG. Ciência e Agrotecnologia, Lavras, v. 1, n. 6, p. 18621866, nov./dez. 2007.

ENCISO, T. O.; ZAZUETA, Ma. E. I.; RANGEL, Ma. D. M.; TORRES, J. B. V.; ROMERO, M. V.; VERDUGO, S. H. Calidad postcosecha de frutos de pitahaya (Hylocereus undatus Haw.) cosechados en tres estados de madurez. Revista Fitotecnia Mexicana, Chapingo, v. 34, n. 1, p. 63-72, 2011.

FERREIRA, D. F. Sisvar: a computer statistical analysis system. Ciência e Agrotecnologia, Lavras, v. 35, n. 6, p. 1039-1042, 2011.

FISCHER, I. H.; TOZZE JÚNIOR, H. J.; ARRUDA, M. C. de; MASSOLA, N. S. Pós-colheita de abacates 'Fuerte' e 'Hass': características físicas e químicas, danos e controle de doenças. Semina: Ciências Agrárias, Londrina, v. 32, n. 1, p. 209-220, jan./mar. 2011.

FORNI, E.; POLESELLO, A.; MONTEFIORI, D.; MAESTRELLI, A. High-performance liquid chromatographic analysis of the pigments of bloodred prickly pear (Opuntia ficus indica).Journal of Chromatography, Amsterdam, v. 593, n. 1-2, p. 177-183, feb. 1992.
HERBACH, K. M.; ROHE, M.; STINTZING, F. C.; CARLE, R. Structural and chromatic stability of purple pitaya (Hylocereus polyrhizus [Weber] Britton \& Rose) betacyanins as affected by the juice matrix and selected additives. Food Research International, Barking, v. 39, n. 10, p. 667-677, dec. 2006.

HERNÁNDEZ, Y. D. O. Hacia aconocimiento y a conservación de a pitahaya. Oaxaca: IPN-SIBEJCONACYT-FMCN, 2000. $124 \mathrm{p}$.

INSTITUTO ADOLFO LUTZ - IAL. Normas Análiticas: métodos químicos e físicos para análises de alimentos. 3 . ed. São Paulo: IAL, 1985. v. 1, 533 p.

LE BELLEC, F.; VAILLANT, F.; IMBERT, E. Pitahaya (Hylocereus spp.): a new crop, a market with a future. Fruits, Paris, v. 61, n. 4, p. 237-250, aug. 2006.

MERTEN, S. A review of Hylocereus production in the United States. Journal of the Professional Association for Cactus Development, Davis, v. 5, n. 1, p. 98-105, nov. 2003.

NERD, A.; MIZRAHI, Y. Effect of ripening stage on fruit quality after storage of yellow pitaya. Postharvest Biology and Technology, Amsterdam, v. 15, n. 1, p. 99105, feb. 1999.

ORTIZ-HERNÁNDEZ, Y. D.; CARRILLO-SALAZAR, J. A. Pitahaya (Hylocereus spp.): a short review. Comunicata Scientiae, Bom Jesus, v. 3, n. 4, p. 220-237, 2012.

RAMÍREZ, M. F. J. Caracterización y compatibilidad en pitahaya (Hylocereus spp.).1999. Tesis (Doctorado en Agronomía) - Universidad Autónoma Chapingo, Chapingo.

RODRÍGUEZ, R. D. A.; PILAR, P. G. M. del; DIEGO, M. L.; GERHARD, F.; ANTONIO, G. V. J. Efecto de dos índices de madurez y dos temperaturas de almacenamiento sobre el comportamiento en poscosecha de la pitahaya amarilla (Selenicereus megalanthus Haw.). Revista Faculdade Nacional de Agronomia, Medellín, v. 58, n. 2, p. 2837-2857, jul./dic. 2005.

SHETTY, A. A.; RANA, M. K.; PREETHAM, S. P. Cactus: a medicinal food. Journal of Food Science and Technology, Trivandrum, v. 49, n. 5, p. 530-536, may 2012.

SILVA, A. P.; ABREU, C. M. P. de; CÔRREA, A. D.; ASMAR, S. A. Modificações nas atividades da poligalacturonase e pectinametilesterase em morangos armazenados a temperatura ambiente. Ciência e Agrotecnologia, Lavras, v. 33, p. 1953-1958, 2009. Número Especial. 
SILVA, C. de. S.; LIMA, L. C.; SANTOS, H. S.; CAMILI, E. C.; VIEIRA, C. R. Y. I.; MARTIN, C. da. $\mathrm{S}$. Amadurecimento da banana-prata climatizada em diferentes dias após a colheita. Ciência e Agrotecnologia, Lavras, v. 30, n. 1, p. 103-111, nov./dez. 2006.

SILVA, T. V.; RESENDE, E. D. de; VIANA, A. P.; ROSA, R. C. C.; PEREIRA, S. M. de F.; CARLOS, L. de A.; VITORAZI, L. Influência dos estádios de maturação na qualidade do suco do maracujá-amarelo. Revista Brasileira de Fruticultura, Jaboticabal, v. 27, n. 3, p. 472-475, 2005.

TO, L. V.; NGU, N.; DUC, N. D.; HUONG, H. T. T. Dragon fruit quality end storage life: effect of harvest time use of plant growth regulators and modified atmosphere packaging. Acta Horticulturae, The Hague, v. 2, n. 575, p. 611-621, 2002.

TUCKER, G. A. Introduction. In: SEYMOUR, G. B.; TAYLOR, J. E.; TUCKER, G. A. (Ed.). Biochemistry of fruit ripening. London: Chapmal \& Hall, 1993. p. 2-51.
WILLS, R., MCGLASSON, B.; GRAHAM, D.; JOYCE, D. Postharvest: an introduction to the physiology and handing of fruit, vegetables and ornamentals. $4^{\text {th }}$ ed. Melbourne: New South Wales University, 1998. 262 p.

YAH, A. R. C.; PEREIRA, S. S.; SILVA, M. E.; SAÑUDO, R. B.; VELOZ, C. S.; DUCH, E. S. Variacion de las principales características de la pitahaya (Hylocereus undatus) durante su maturacion postcosecha. Horticultura Mexicana, v. 7, n. 3, p. 419-425, 1999.

YAH, A. R. C.; PEREIRA, S. S.; VELOZ, C. S.; SAÑUDO, R. B.; DUCH, E. S. Cambios físicos, químicos y sensoriales en frutos de pitahaya (Hylocereus undatus) durante su desarrollo. Revista Fitotecnia Mexicana, Chapingo, v. 31, n. 1, p. 1-5, 2008.

ZEE, F.; YEN, C. R.; NISHINA, M. Pitaya: dragon fruit, strawberry pearl. Fruits e Nuts, Hawai, v. 9, n. 2, p. 1-3, 2004. 
